\title{
Por QUe a disciplina de Química Geral ReProva TANTO?
}

\author{
WHY DOES THE GENERAL CHEMISTRY DISCIPLINE FAIL SO MUCH?
}

DOI: http://dx.doi.org/10.23926/RPD.2526-2149.2020.v5.n1.p449-468.id643

\section{Eduardo Ribeiro Mueller \\ Doutor em Educação em \\ Ciências e Matemática \\ (REAMEC/UFMT) \\ Professor na Universidade \\ Federal de Mato Grosso \\ (UFMT/Campus Araguaia) \\ edurmuller@hotmail.com}

\section{Letícia Vanin}

Mestra em Educação

(UFMT)

Professora no Instituto

Federal de Mato Grosso

(IFMT/Campus Barra do

Garças)

leticiavanin@yahoo.com.br

\section{Gabriel Bezerra \\ Cardoso}

Graduando em Química

(UFMT/Campus Araguaia)

Gabrielcbezerra1547@gmail .com

\section{Rans Miler Pereira \\ Dantas \\ Graduando em Química \\ (UFMT/Campus Araguaia) \\ ransmiler@gmail.com}

Resumo: Este trabalho faz parte de uma abordagem investigativa denominada Transição Ensino Médio/Universidade: conflitos do acesso ao ensino superior em Química. Neste artigo o objetivo foi verificar contradições estatísticas relacionadas a aprovações e reprovações na educação básica e no ensino superior em Química, e investigar a relação entre os altos índices de reprovação na disciplina de Química Geral e o perfil dos estudantes que ingressam no curso de Licenciatura em Química da UFMT - Campus Araguaia. Para isso, realizamos coleta de dados (matriculados, aprovados e reprovados) junto ao curso de Licenciatura em química e junto à SEDUC-MT, resultados de 2014 a 2018, e realizamos observação participante na turma de química geral do semestre 2019/1. Os resultados comprovaram nossa hipótese, de que há distinção quanto à aferição de notas e quanto ao nível de dificuldade das avaliações praticadas. Concluímos que, em ambos os casos, a aprendizagem não está sendo alcançada de modo satisfatório.

Palavras-chave: Química Geral; Aprovação; Reprovação; Aprendizagem.

\begin{abstract}
This work is part of an investigative approach called Transition High School/ University: conflicts of access to higher education in Chemistry. In this article the objective was to verify statistical contradictions related to pass and fail in Basic Education and Higher Education in Chemistry, and to investigate the relationship between the high failure rates in the discipline of General Chemistry and the profile of students who enter the undergraduate course in Chemistry at UFMT - Campus Araguaia. For this, we performed data collection (enrolled, approved and disapproved) with the chemistry degree course and with SEDUCMT, results from 2014 to 2018, and performed participant observation in the general chemistry class of the semester 2019/1. The results confirmed our hypothesis, that there is a distinction regarding the assessment of grades and the level of difficulty of the practiced evaluations. We conclude that, in both cases, learning is not being achieved satisfactorily.
\end{abstract}

Keywords: General chemistry; Approval; Disapproval; Learning. 


\section{INTRODUÇÃO}

Os dados que apresentamos aqui foram extraídos de uma pesquisa maior, em andamento, denominada Transição Ensino Médio/Universidade: conflitos do acesso ao ensino superior em Química. Neste trabalho nosso objetivo foi verificar contradições estatísticas relacionadas a aprovações e reprovações na educação básica e no ensino superior em Química, e investigar a relação entre os altos índices de reprovação na disciplina de Química Geral e o perfil dos estudantes que ingressam no curso de Licenciatura em Química da UFMT - Campus Araguaia.

A Licenciatura em Química em questão é um curso noturno de 4 anos (8 semestres), mas a média geral de tempo dos concluintes é de 4,8 anos. Em 2019/1 tivemos 45 ingressantes; dias antes, na formatura 2018/2 só havia 5 alunas. Essa discrepância entre o número de ingressantes e número de concluintes tem o peso das reprovações (em 2018/1, por exemplo, $78 \%$ dos alunos reprovaram por média, ou por média e falta na disciplina de química geral), dos abandonos, das dificuldades de aprendizagem, da associação trabalho/estudo, dentre outros. Acreditamos que a elucidação de causas junto aos ingressantes poderá nos ajudar a entender melhor o que fazer diante dessa realidade.

Uma das hipóteses deste trabalho é que a aprovação na educação básica não está refletindo aprendizagem em química. Os métodos e avaliações adotadas por professores podem estar gerando resultados falsos, contemplando apenas respostas corretas em provas e não aprendizagem de fato. Para propor essa contradição, nos baseamos nos resultados obtidos nas disciplinas de Química Geral ofertadas no período 2014 a 2018 no curso supracitado.

Corroborando, nossa observação participante constatou relevantes dificuldades de abstração de conceitos básicos, ou seja, nossos alunos chegam ao ensino superior em Química sem saberem definir um átomo, um elemento químico ou uma substância; não realizam corretamente uma consulta na tabela periódica ou um cálculo de densidade. É nesse contexto que sugerimos que aprovações sucessivas na educação básica não estão refletindo em aprendizagem. A ideia desta pesquisa é desvelar este problema, propondo soluções.

\section{REFERENCIAL TEÓRICO}

\subsection{RECOMENDAÇÕES AO ENSINO DE QUÍMICA}

Nossos dados mostram que a aprovação em química no ensino médio, no município de Barra do Garças, gira em torno de 70\%. Na disciplina de Química Geral, na universidade, onde são abordados os mesmos conteúdos do ensino médio, a aprovação não ultrapassa a média de 
39\% (Gráfico 2). Temos aí não só a evidenciação de uma contradição da aprendizagem, mas também um conflito do ensino, que conforme aponta Schnetzler (2010), necessita transitar entre os níveis de conhecimento químico diversificando formas de ensinar, sobretudo pelo empoderamento das questões que envolvem conhecer como o sujeito apreende a construção de seu conhecimento.

Também é inerente a este conflito a formatação dos cursos de Química secundaristas e superiores, os quais mantém padrões avaliativos alicerçados na Iniciação Resposta Feedback IRF$^{1}$ (MORTIMER, 2000), assim como é sobrepujante o padrão metodológico baseado na tendência tradicional liberal.

Ainda muito viva entre nós, esta tendência defendia que o papel do professor deveria estar "focado em vigiar os alunos, aconselhar, ensinar a matéria ou conteúdo, que deveria ser denso e livresco, e corrigir. Suas aulas deveriam ser expositivas, organizadas de acordo com uma sequência fixa, baseada na repetição e na memorização" (QUEIROZ; MOITA, 2007, p. 3).

Serve-nos de parâmetro um texto escrito pelo professor Áttico Chassot (2010), chamado "Diálogos de Aprendentes", em que ele sistematiza distintas falas provenientes de um "diálogo internético" (p. 23) com diversos interlocutores, de diferentes níveis de formação acadêmica. Para dialogar, Chassot utilizou a estudante Maria Clara e o professor Giordano.

Na primeira mensagem escrita por Maria Clara, ela assumiu não estar satisfeita com a formação em química oferecida por sua faculdade, e para justificar esta insatisfação disse:

[...] as disciplinas do curso, na maior parte, parecem pertencer a dois blocos completamente distintos: As disciplinas de Química - formatadas por conteúdos abstratos, assépticos e desvinculados da realidade, e As disciplinas de Formação Pedagógica - marcadas por quase quimeras, que parecem desconhecer o chão da escola. Ocorre que esses dois blocos estão acondicionados (talvez a melhor palavra seja: engessados) em muros rígidos, intransponíveis e incomunicáveis (entre si) (CHASSOT, 2010, p. 24 - itálicos do autor).

Em seguida, Maria Clara conclui questionando o professor Giordano: "o senhor concorda com minha reflexão de que os professores não devem privilegiar tanto os conteúdos de Química e mais uma Educação nas Ciências ligada à realidade onde estou inserida?" (CHASSOT, 2010, p. 25).

Em sua resposta, o professor Giordano (o próprio Chassot em seu personagem) tece um diálogo com textos de sua autoria como forma de alimentar epistemologicamente a opinião que daria. Para esta defesa, destaca o histórico tradicionalismo da escola, afirmando que esta não

\footnotetext{
${ }^{1}$ Padrão em que o professor apenas transmite informações e depois requisita essas informações num teste para aferir nota.
} 
mudou, e sim foi mudada, sobretudo pela mudança comportamental das pessoas que a constituem.

Ele chamou essa mudança de "neopatia" (CHASSOT, 2010, p. 27), que definiu como manifestação doentia de ter tudo novo: computador mais moderno, último modelo de celular, televisão de plasma etc., que afetou a escola por descaracterizá-la de sua histórica função de centro irradiador do conhecimento, em que verdades irrefutáveis eram legitimadas por professores e professoras.

Como consequência da existência de pessoas neopáticas em ambiente escolar, a escola de hoje é assolada por informações, pois o conhecimento chega a ela de todas as maneiras e com as mais diferentes qualidades. Finalizou respondendo:

\footnotetext{
Esta é a mudança radical que ocorre nela hoje. É evidente que essa Escola exige outras posturas de professoras e professores. O transmissor de conteúdos já era. Hoje precisamos mudar de informadores para formadores. Parte de nossas tarefas, portanto, é ajudar a formar um pensamento crítico que permita a nossos alunos discriminar "verdades" de falácias e privilegiar - dentro do extenso repertório de conhecimentos - aqueles conteúdos que possibilitem uma melhor qualidade de vida (CHASSOT, 2010 , p. 28 - grifo nosso).
}

Em pesquisa durante seu doutorado (CHASSOT, 1995), este mesmo autor comprovou como o ensino conteudista está, ao menos teoricamente, fadado ao esquecimento. Esta comprovação deve nos servir de amparo ao necessário questionamento do processo de ensino aprendizagem focado na transmissão de informações. No extenso leque de contradições e conflitos que envolvem ensinar e aprender química, tanto na educação básica como no ensino superior, a problematização da aprovação/reprovação carrega, na sua compreensão, a importância de não promovermos mais exclusões num país de classes sociais já tão extremadas. Nossa pesquisa tem esse foco, pois tem sua preocupação voltada à diminuição das reprovações e evasões de alunos iniciantes.

\subsection{O QUE NOS DIZEM ALGUMAS PESQUISAS SOBRE REPROVAÇÃO?}

Reprovação no ensino superior é um tema com relevante abordagem no meio acadêmico (OLIVEIRA; RAAD, 2012; CURY, 2012; SILVA, 2013). Nossas hipóteses têm, nesse contexto, o respaldo das investigações de Belo, Leite e Meotti (2019), quando apontam que discentes que ingressam no ensino superior trazem consigo problemas relacionados à má formação do ensino médio interligados à falta de qualificação dos professores. Esta contradição que relaciona aprovação (ensino médio) e reprovação (ensino superior) tem um produto comum, ou seja, nem lá nem cá, seja quando se aprova ou quando se reprova, não se alcança aprendizagem satisfatória. 
Percebemos que determinadas disciplinas possuem uma cultura escolar de reprovação enraizada, entre elas o cálculo diferencial e integral (OLIVEIRA; RAAD, 2012). Nos atrevemos a alocar a Química Geral nesse grupo, entendendo que sua história acadêmica acabou por naturalizar a reprovação, não demonstrando evolução didática relacionada ao conjunto de práticas que a constitui, não modernizando os discursos que a legitimam como disciplina acadêmica (VIÑAO, 2008), e pior, não diversificando a forma como seus conteúdos são ensinados em detrimento da realidade cognitiva do público que nela se matriculam.

\begin{abstract}
Uma pesquisa realizada na Universidade de Évora e divulgada por vieira e Cristóvão (2009) tem como resultados que, dentre os principais motivos de reprovação apontados pelos alunos participantes do estudo que haviam sido reprovados em disciplinas de graduação estariam: a falta de motivação, com 40,22\% das respostas, seguida pela justificativa baseada no desempenho pedagógico dos docentes, com $35,87 \%$ e por falta de adequação entre conhecimentos prévios e pré-requisitos necessários para o curso da disciplina, como $29,35 \%$ das respostas. O relacionamento entre docente(s) e alunos também apareceu como fator que motivou reprovação de alunos em 20, 65\% (CURY, 2012, p. 66).
\end{abstract}

Se existe, por um lado, uma cultura escolar que dificulta a aproximação entre ensino e aprendizagem, do outro existem estudantes insatisfeitos consigo mesmo e com seus professores. Não raro ouvimos estudantes criticarem disciplinas nas quais passam com facilidade, e também disciplinas nas quais reprovam. Há um mérito maior atribuído pelo próprio aluno às disciplinas que mais reprovam, como se estas estivessem a representar um curso forte, no bojo do qual a formação se dá com mais qualidade. Estes aspectos, absolutamente preponderantes no quadro de reprovações e abandonos analisados por nós, mostram a necessidade de desenvolvimento de pesquisas capazes de apontar soluções nesse cenário.

Numa dessas pesquisas, realizada na Universidade Federal de Uberlândia, Araújo (2003) voltou o foco de suas entrevistas ao sentido dado pelos sujeitos às reprovações. A autora considerou tanto alunos como professores no grupo pesquisado. $\mathrm{Na}$ opinião dos universitários, os principais sentidos atribuídos foram a desistência de discentes, falta de compromisso com os estudos, falta de frequência às aulas, crenças repassadas por veteranos acerca da rigidez de determinados professores e do quão difíceis são os conteúdos ministrados nas disciplinas. Os professores ressaltaram, dentre outros, a falta de didática para ministrar conteúdo, falha na preparação das aulas, falta de envolvimento na relação com alunos e falta de vinculação do conteúdo às expectativas quanto a profissão.

Para Silva, Mainier e Passos (2006), a falta de diálogo entre professores do ensino superior e os alunos ingressantes é um ponto de conflito que pode se transformar em bloqueios de aprendizagem, ou seja, os professores dizem que ensinam, mas os alunos efetivamente não 
aprendem. Assim, "olhando os fatos por uma ótica pedagógica, verifica-se que tais problemas estão relacionados com a incompatibilidade da metodologia de ensino adotada e o nível de maturidade dos alunos ingressantes" (SILVA; MAINIER; PASSOS, 2006, p. 268).

Tinto (1993), em pesquisa sobre a evasão, afirmou que ela decorre das influências que as comunidades sociais e intelectuais exercem sobre a vontade dos estudantes em permanecer na faculdade. Para ele, quatro conjuntos de fatores pesam sobre a decisão de evadir: atributos prévios à entrada na faculdade, como background familiar, habilidade e escolaridade; a interrelação entre os objetivos e comprometimento da instituição e dos alunos; o conjunto de relações formais e informais estabelecido no ambiente acadêmico e no social, como performance acadêmica, interação com os funcionários da instituição, atividades extracurriculares; e, por fim, a integração acadêmica e a integração social que os itens anteriores proporcionam.

Esta pesquisa busca corroborar, ao mesmo tempo com dados da nossa realidade e com problematizações acadêmicas e sociais, estas últimas com respaldo na produção científica acerca das reprovações e evasões. Fazer o aluno permanecer na instituição escolhida, superando os desafios da sua formação é responsabilidade de todos nós que trabalhamos com educação.

\section{Metodologia}

Considerando que todo problema de pesquisa requisita, no contexto da investigação, uma escolha metodológica, buscamos na literatura específica aquela que melhor nos representaria e, pela tradição das pesquisas em Ciência Humanas/Educação elegemos a pesquisa qualitativa. Creswell (2014) nos fornece uma primeira definição: "A pesquisa qualitativa começa com pressupostos e o uso de estruturas interpretativas/teóricas que informam o estudo dos problemas da pesquisa, abordando os significados que os indivíduos ou grupos atribuem a um problema social ou humano" (p. 49 e 50 - grifos do autor).

A pesquisa qualitativa não está moldada na mensuração, a exemplo de muitos casos das ciências naturais, e quando a adotamos não estamos interessados em padronizar uma situação, muito menos garantir a representatividade por amostragem aleatória dos participantes (FLICK, 2013). O foco da pesquisa qualitativa é compreender e aprofundar os fenômenos que são explorados a partir da perspectiva dos participantes em um ambiente natural e em relação ao contexto (SAMPIERI, 2013).

Nesse sentido, buscar compreender a perspectiva dos participantes (indivíduos ou grupos pequenos de pessoas que serão pesquisados) sobre fenômenos inerentes ao seu trabalho 
ou a sua vida, nos aprofundarmos em suas experiências, pontos de vista, opiniões e significados, na forma como percebem sua realidade (SAMPIERI, 2013), configura enfoque com postura metodológica ancorada na pesquisa qualitativa.

A opção pela pesquisa participante como suporte metodológico tem, na decisão, o peso da ideia inicial de conhecer primeiro o problema. Hipoteticamente sabemos que a aprendizagem em química no ensino médio é ruim, mesmo havendo aprovação, assim como também o é na disciplina de Química Geral (na universidade). Entender as nuances deste problema, sem inicialmente tentar manipular a realidade na qual ele se acentuou, nos orientará melhor no caminho das decisões futuras.

Conforme nos alerta Chizzotti (2006), a pesquisa participante é um conceito elástico, “abrigando concepções e práticas de investigação sob diferentes nomes, que partem de premissas similares e revelam diferentes aspectos do processo participativo com a finalidade de orientar a prática" (p. 90). A compreensão, portanto, dos conflitos de aprendizagem de um determinado grupo de alunos, por meio da observação de suas aulas teóricas e práticas, terá muito do ponto de vista do observador, supostamente orientado pela sua formação e concepções educacionais.

De qualquer maneira, a pesquisa participante não é uma representação individual, mas sim uma prática social. Se o problema não foi inventado, e este não foi (a dificuldade de aprendizagem em química é aparente), ao passo que sua existência gera conflitos e exclusão social (por exemplo, muitas reprovações e desistências), incluir neste lócus a pesquisa participante pode resultar em melhoria para todos os sujeitos envolvidos, incluindo professores e alunos. Elucidar a realidade com resultados significa alcançar os meios necessários para operar mudanças nas condições opressoras do ensinar e aprender química, da forma como está hoje.

\footnotetext{
A pesquisa significa investigar sistematicamente uma situação problemática em uma dada comunidade ou em uma organização, propondo-se aos membros de um grupo participarem, ativamente, com pesquisadores treinados, da definição do problema a ser investigado. Juntos promovem ampla participação no processo de coleta e análise de informações necessárias para aprofundar o conhecimento desse problema e deliberarem, partilhadamente, sobre as ações mais consequentes que levem a uma situação mais justa e satisfatória aos usuários (CHIZZOTTI, 2006, p. 93 - grifo nosso).
}

Do ponto de vista coletivo, dentro de um curso de licenciatura, questões de natureza análoga como proposta por esta pesquisa são tratadas apenas superficialmente, dado que a forma como cada docente conduz suas disciplinas tem apenas uma avaliação estrutural, realizada pelo colegiado, ou seja, confere-se e aprova-se o plano de ensino, monitora-se o 
acontecimento das aulas e aguarda o resultado final ser entregue. O que propomos aqui poderá oportunizar a estes colegiados uma deliberação partilhada, como nos alerta Chizzotti (2006), sobre ações mais consequentes acerca das altas reprovações, que levem a uma situação mais justa e satisfatória aos alunos. Ser docente em um curso e poder desenvolver uma pesquisa que o favoreça é um privilégio.

\subsection{Procedimentos metodológicos}

Inicialmente realizou-se um levantamento de dados junto à Secretaria de Estado de Educação - SEDUC/MT sobre aprovações e reprovações nas disciplinas de química, no período de 2014 a 2018, desenvolvidas em oito escolas estaduais do Município de Barra do Garças/MT. Concomitante levantou-se, junto à coordenação de curso, as taxas de aprovação e reprovação da disciplina de Química Geral (também entre 2014 a 2018) no curso de Química da UFMT/Campus Araguaia.

A análise desses dados foi feita por meio de um confronto de resultados (estatística geral) no sentido de compreender como a química está aferindo nota na educação básica e na disciplina de Química Geral (ensino superior), e o quanto essa nota pode refletir aprendizagem dentro deste contexto, considerando os percentuais de aprovação e reprovação, tanto na educação básica como no ensino superior. A interpretação dada a esses resultados não foi puramente estatística, pois esta pesquisa realizou observação participante na disciplina de Química Geral (curso de Licenciatura em Química supracitado), buscando compreender nuances da (não) aprendizagem e sua relação com as aprovações/reprovações.

Num segundo momento, realizou-se uma coleta de dados junto a um grupo de calouros deste mesmo curso, todos matriculados e frequentando a disciplina de Química Geral - semestre 2019/1. A seleção dos participantes se deu por convite, e todos que aceitaram, 60\% dos alunos, responderam a um questionário semiestruturado. As questões pontuaram a idade, percentual dos que trabalham, ano do término do ensino médio, percentual dos moradores locais, frequência dos alunos nas aulas teóricas e práticas, frequência na monitoria da referida disciplina e notas dos alunos na primeira avaliação teórica.

De posse desses dados evidenciamos contradições estatísticas, considerando o atual quadro de aprovação/reprovação, tanto na educação básica como no ensino superior, em detrimento da aprendizagem, e também analisamos o perfil do nosso estudante ingressante, inferindo sobre causas contribuidoras de reprovações. 


\section{Resultados}

\subsection{O QUE AS TAXAS DE APROVAÇÃO, REPROVAÇÃO E ABANDONOS SÃO CAPAZES DE NOS} REVELAR?

Apresentamos inicialmente, nos Gráficos 1 e 2, o panorama da disciplina de Química Geral do Curso de Licenciatura em Química da UFMT - Campus Universitário do Araguaia, no período 2014 a 2018. Esta disciplina é ofertada sempre no primeiro semestre de cada ano letivo, momento em que o curso recebe seus calouros, exceção de 2017, quando o curso ofertou, em caráter especial, uma turma no segundo semestre, onde somente 12 alunos se matricularam. A maioria dos alunos que ingressam nesse curso vêm de escolas públicas de Barra do Garças/MT, cujos dados sobre aprovação e reprovação apresentamos na sequência.

No Gráfico 1 vejam que, embora o curso oferte 45 vagas para entrada de calouros, nem sempre todos se matriculam. Alguns desistem antes de iniciar o semestre letivo em função de abertura de vagas em outros cursos pelos quais optaram no SISU - Sistema de Seleção Unificado - antes da química. Os dados mostram que, das seis disciplinas ofertadas, em somente duas ocasiões (2014/1 e 2015/1) houveram 100\% (cem por cento) de matriculados. Os três alunos a mais em 2015/1 provavelmente são repetentes.

Gráfico 1 - Alunos matriculados em Química Geral no período de 2014 a 2018 - Curso de Licenciatura em Química

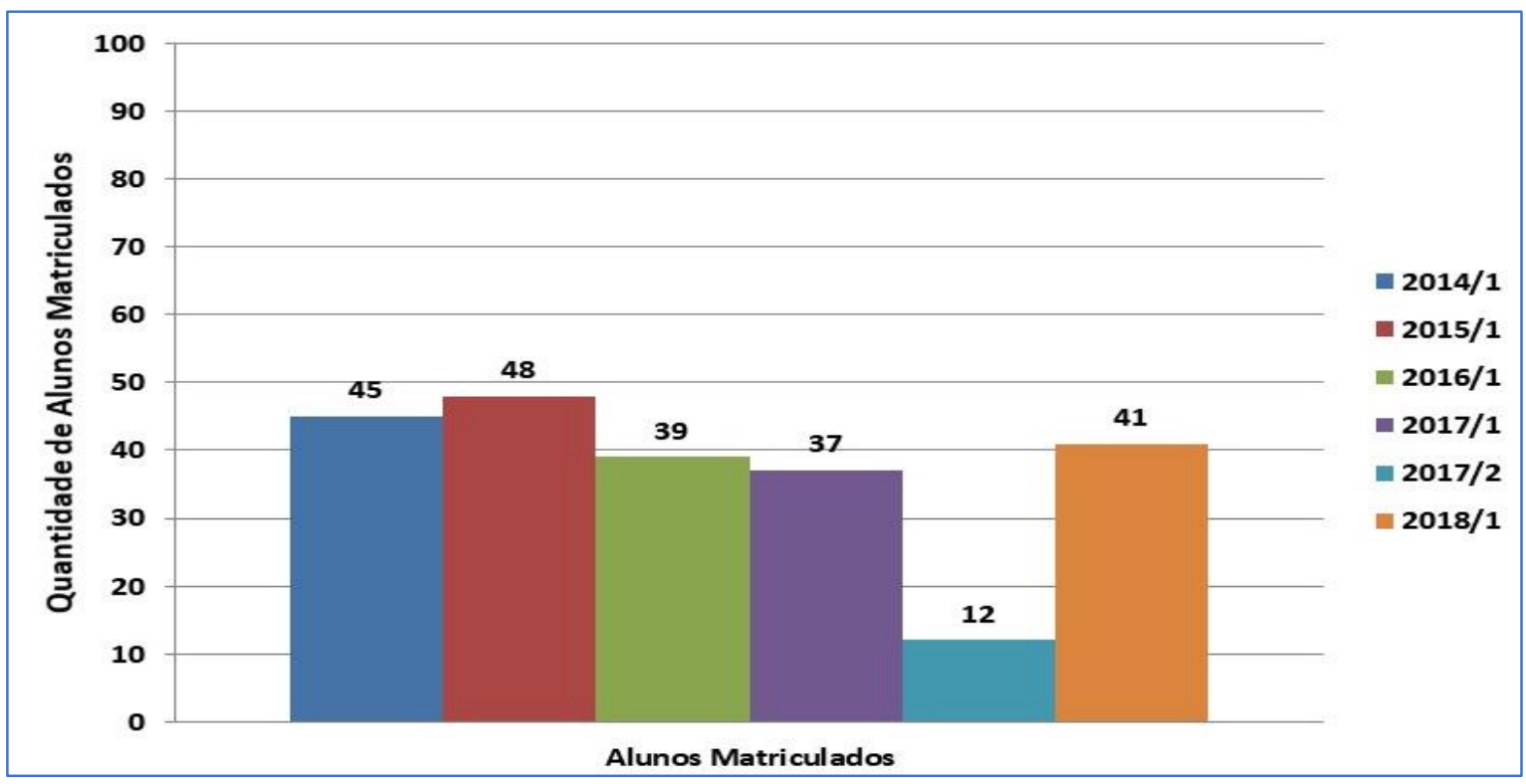

Fonte: Curso de Licenciatura em Química - UFMT CUA (2019). 
Gráfico 2 - Resultados da disciplina de Química Geral no período 2014 a 2018 - Curso de Licenciatura em Química do Campus Universitário do Araguaia

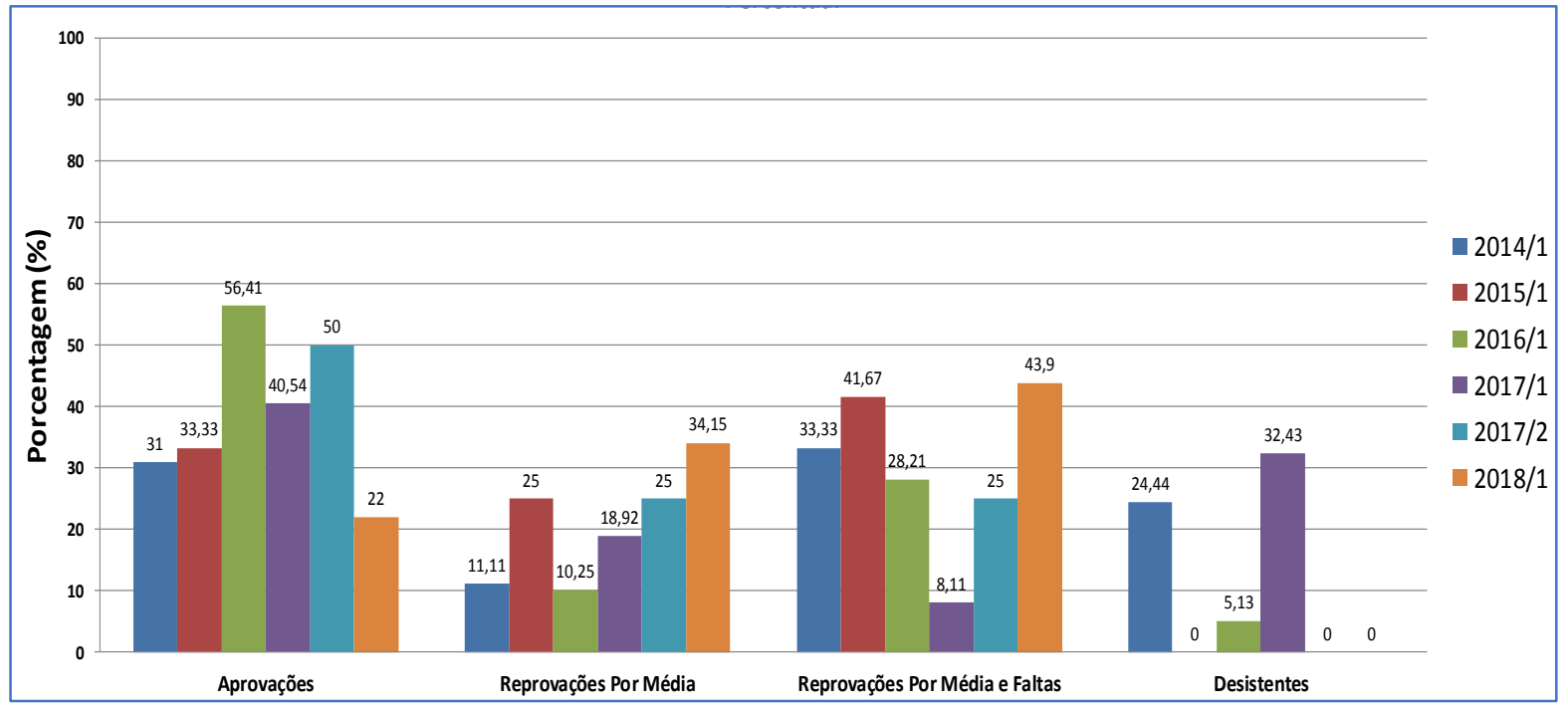

Fonte: Curso de Licenciatura em Química - UFMT CUA (2019).

Observe que em apenas duas situações o índice de aprovação alcançou 50\% (Gráfico 2). A média geral foi de $38,88 \%$, tendo o pior resultado em $2018 / 1$, com apenas $22 \%$ dos alunos aprovados. O gráfico ainda mostra que, mesmo quando não há desistências, como em 2015/1 e 2018/1, as aprovações mantém-se baixas. Considerando esses resultados, podemos concluir que o percentual de alunos em condições de acompanhar os estudos propostos pela disciplina de Química Geral se mantém abaixo da metade da turma, ou seja, embora tenham sido aprovados na educação básica e ENEM (Exame Nacional do Ensino Médio), sua inclusão ainda requer um investimento maior em aprendizagem.

Importante salientar que há uma distinção entre tirar nota e aprender. Como já mencionado, existem métodos com padrões que valorizam o alcance da nota, por exemplo a prática de decorebas e avaliações por testes, por meio dos quais a abstração, grau máximo de generalização, não se verifica. Sem essa capacidade de generalizar diante do conceito, ou seja, de aplicá-lo em situações distintas, a tomada de consciência é quase sempre sincrética, operando formas de pensamento ainda muito restritas em relação aos conceitos verdadeiros (VIGOTSKI, 2008).

Interpostas entre as notas e o aprendizado estão as avaliações, muitas vezes reduzidas a testes ou exames. Cipriano Luckesi nos diz que o papel da avaliação é diagnosticar a situação da aprendizagem, tendo em vista subsidiar a tomada de decisão para a melhoria da qualidade do desempenho do educando (LUCKESI, 2011). Nesse contexto, a avaliação, segundo o autor, é processual e dinâmica. Na medida em que busca meios pelos quais todos possam aprender o que é necessário para o próprio desenvolvimento, é inclusiva. Sendo inclusiva é, antes de tudo, 
um ato democrático. Luckesi relata que, em vez de avaliação, o que se pratica nas escolas são os exames, uma vez que as dificuldades apresentadas pelos alunos não são diagnosticadas para subsidiar uma intervenção adequada, mas são classificadas, tendo em vista a aprovação ou a reprovação.

Na sequência apresentamos, no Gráfico 3, os resultados da disciplina de química das escolas estaduais de Barra do Garças/MT, origem da maior parte dos nossos alunos. As escolas representadas são as estaduais Antônio Cristino Côrtes, Deputado Norberto Schwantes, Francisco Dourado, Heronides Araújo, Irmã Diva Pimentel, Marechal Eurico Gaspar Dutra, Nossa Senhora da Guia e Maria de Lourdes Hora Moraes.

Gráfico 3 - Desempenho geral das escolas estaduais de ensino médio de Barra do Garças/MT - período de 2014 a $2018-10.056$ alunos matriculados

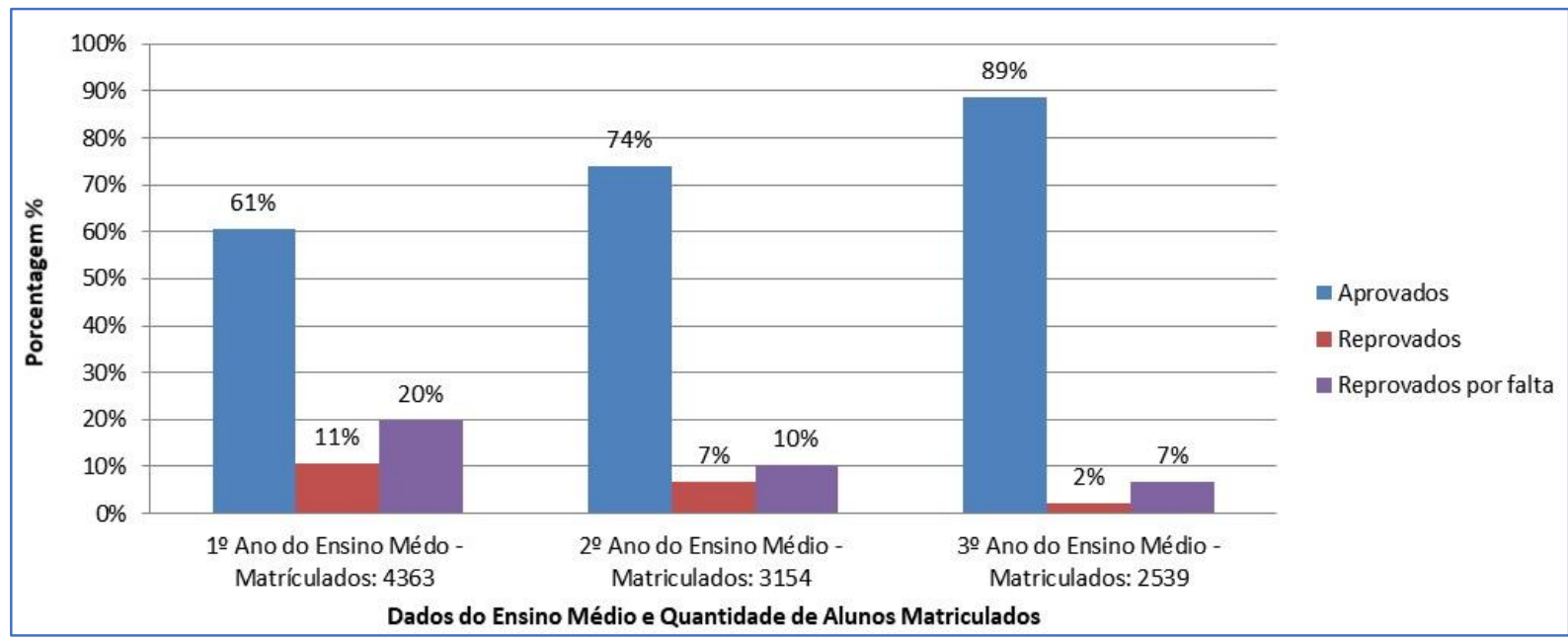

Fonte: Coordenação de Ensino Médio - Secretaria de Estado da Educação - SEDUC MT (2019).

O Gráfico 3 mostra um padrão para as escolas estaduais de Barra do Garças em relação aos dados colhidos, ou seja, à medida que o número de alunos matriculados cai (do primeiro para o terceiro ano do ensino médio), aumenta a aprovação. Podemos, de certa forma, comparar o primeiro ano do ensino médio com o primeiro semestre na universidade, ou seja, na universidade também é possível que a reprovação perca espaço, dado o amadurecimento social e cognitivo do aluno com o passar do tempo dentro de cada curso. Nessas duas etapas escolares, o início tem se mostrado mais conflituoso.

Outra questão revelada pelo Gráfico 3 é que a aparente diminuição das reprovações (consequentemente aumento das aprovações) e dos abandonos favorecem o aumento do IDEB (Índice de Desenvolvimento da Educação Básica) dessas unidades escolares. O cálculo leva em conta o tempo médio para se concluir determinado período escolar, neste caso o ensino médio, 
o que pode induzir as administrações escolares a cuidados maiores relacionados às reprovações e abandonos.

Conforme hipoteticamente prevíamos, as taxas de aprovação em química são maiores na educação básica em relação à disciplina de Química Geral. Este dado em si não é conclusivo para inferirmos sobre a aprendizagem, mas ele aponta, sem dúvida, para uma importante contradição: qual distinção de parâmetros de aferição de notas existe entre a educação básica, representada pelo ensino médio e o ensino superior? Estaria esta distinção apenas no grau de dificuldade das avaliações, dado que ambos praticam os testes (provas) com maior ênfase?

É fato que nosso aluno ingressa na universidade com limitações de grande relevância cognitiva, por exemplo, em relação à linguagem química e no trato com operações matemáticas, e que tais limitações têm peso no quadro de insucessos apontados no Gráfico 2. Se é verdade que não estão aprendendo química na educação básica e que isso está sendo preponderante nas reprovações e abandonos na disciplina de Química Geral, repensar a forma como ela (a química geral) está sendo ofertada seria muito importante, sobretudo buscando formas para que o ensino consiga suprir tais limitações de modo a diminuir ou erradicar as reprovações e abandonos.

\subsection{QUE CONCLUSÕES SÃO POSSÍVEIS A PARTIR DO PERFIL DOS CALOUROS?}

No que se refere ao perfil do estudante ingressante, importante inicialmente justificar ao leitor os critérios adotados. A idade e o ano de término do ensino médio têm relevância na aprendizagem na medida que, quanto maior o tempo que a pessoa ficou fora da escola, menor pode ser sua memória conceitual. Outro fator preponderante é o tempo dedicado aos estudos, principalmente na química, que exige abstração de conceitos de outras ciências, como a matemática, física e biologia. Se o estudante é um trabalhador buscando um curso superior, seu esforço para apreender novos conhecimentos será inversamente proporcional ao tempo que terá, e isso influencia na aprendizagem.

No perfil também buscamos saber se o estudante já era morador local. O Campus Universitário do Araguaia está geograficamente localizado nas cidades de Barra do Garças (Campus II) e Pontal do Araguaia (Campus I), ambas cidades de Mato Grosso. Limítrofe delas está o município goiano de Aragarças. Ser morador de alguma dessas três cidades tem o peso de não ter abandonado a família, amigos, de não ter aumentado seu ônus financeiro de subsistência etc. Todos esses fatores influenciam na aprendizagem à medida que podem desencadear desequilíbrios emocionais no aluno iniciante, tais como abandono, saudade da família e vida social restrita. 
Ainda buscamos, ao delinear o perfil, saber se são alunos com histórico de formação em escolas públicas, e se o curso de química representou um desejo ( $1^{\text {a }}$ opção no SISU) ou uma possibilidade ( $2^{\mathrm{a}}$ opção). A associação dessas duas informações pode revelar o caminho das escolhas realizadas pelo aluno ao final do ensino médio, dadas as possibilidades que tinha, a considerar principalmente o nível de sua aprendizagem.

Outros dados foram coletados na monitoria, durante os atendimentos, e com o professor da disciplina, totalizando 21 alunos. São eles:

1. Assiduidade na monitoria e nas aulas;

2. Nota da primeira prova, aplicada em $1^{\circ}$ de julho de 2019 ;

3. Dúvidas expressadas na monitoria, posteriormente classificadas em dois grupos: dificuldades de interlocução com conceitos básicos em função do não domínio da linguagem química, e dificuldades de realização de operações matemáticas básicas.

No que se refere aos resultados, observemos inicialmente os gráficos 4,5 e 6 .

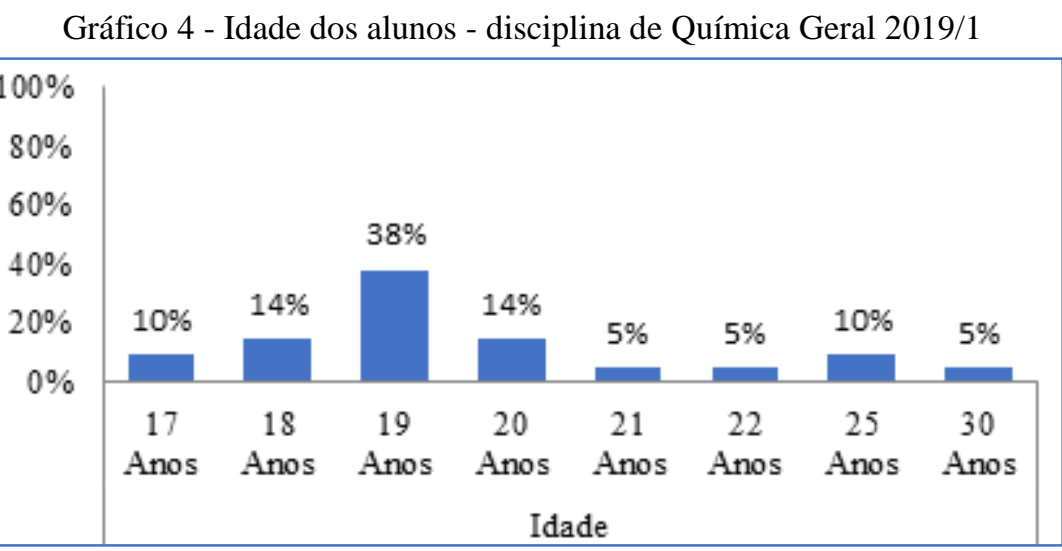

Fonte: Autores (2020).

Gráfico 5 - Percentual dos alunos que trabalham

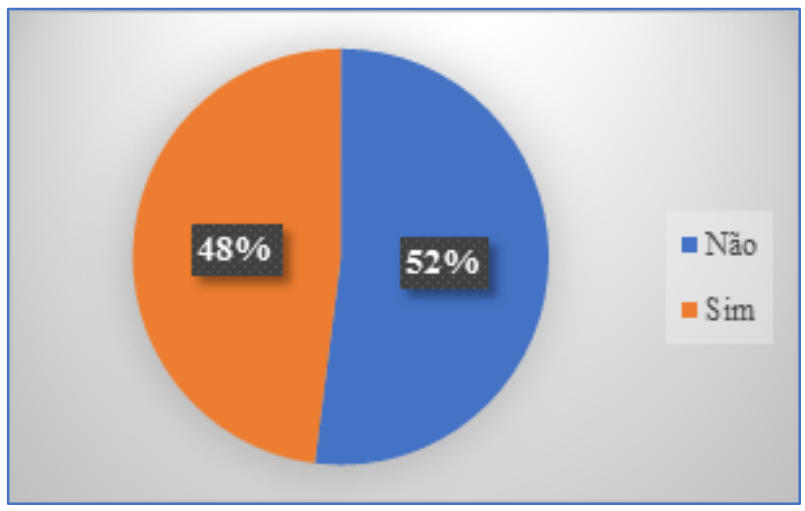

Fonte: Autores (2020). 
Gráfico 6 - Ano de término do Ensino Médio

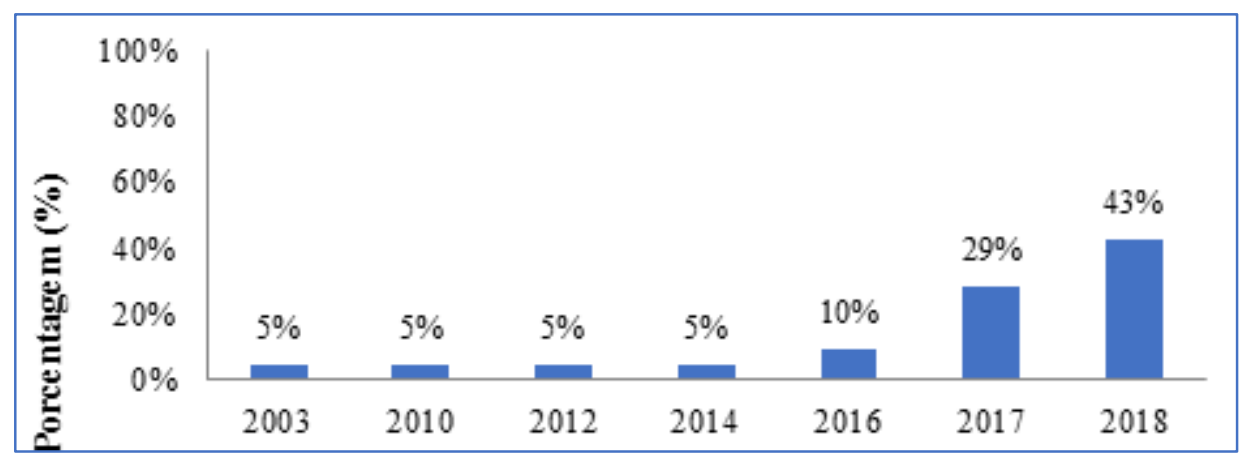

Fonte: Autores (2020)

Há uma alta diversificação de idades em relação aos alunos que compõem a turma, mesmo embora a maioria tenha de 17 a 19 anos, faixa etária mais provável de término do ensino médio para quem não interrompeu seus estudos. Considerando que 39\% deles têm 20 anos ou mais, é possível que tenham ficado algum tempo fora da escola, e por isso apresentem defasagem maior de aprendizagem. Esta percepção é comprovada observando-se os resultados do Gráfico 6, em que $20 \%$ responderam que concluíram seu ensino médio há pelo menos 5 anos.

O Gráfico 5 ainda nos fornece um dado importante, ou seja, praticamente metade da turma são de trabalhadores que estudam. Uma turma com esta configuração provavelmente apresentará níveis de desenvolvimento distintos em relação às respostas buscadas nas avaliações, exigindo, portanto, um olhar mais atento do ensino a que são submetidos, na busca de aprendizagem.

Em relação ao local onde os alunos residem, o Gráfico 7 a seguir nos fornece outro elemento do perfil que corrobora para a complexidade da turma. É alto o percentual de alunos que necessitaram se deslocar de cidade, ou até mesmo de estado, para estarem ali, numa sala de aula de um curso superior. Residir numa cidade diferente pode significar ter que iniciar novas relações sociais praticamente do zero, não ter opções de lazer aos finais de semana, diminuir sobremaneira a qualidade de vida em função do desamparo familiar (ter que cozinhar, lavar, passar, limpar a casa, realizar planejamento financeiro etc.). Todas essas questões tem peso na aprendizagem e desenvolvimento dentro da sala de aula, pois requerem planejamento e disciplina. 
Gráfico 7 - Percentual de alunos moradores de Barra do Garças, Pontal do Araguaia ou Aragarças

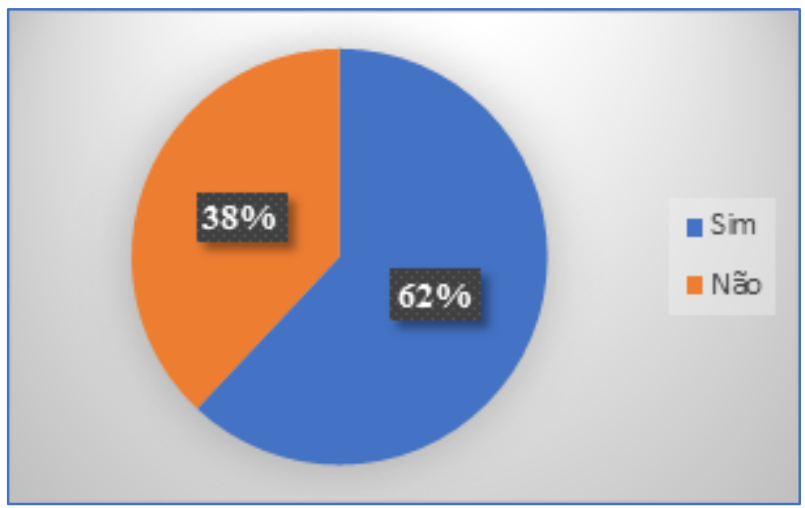

Fonte: Autores (2020).

Os Gráficos 8 e 9 abordam as questões finais do perfil, como o tipo de rede de ensino que os alunos estudaram durante o Ensino Médio e sobre se o curso de Licenciatura em Química foi a primeira opção de curso na inscrição do SISU, como podemos observar a seguir:

Gráfico 8 - Rede de ensino onde cursou Ensino Médio

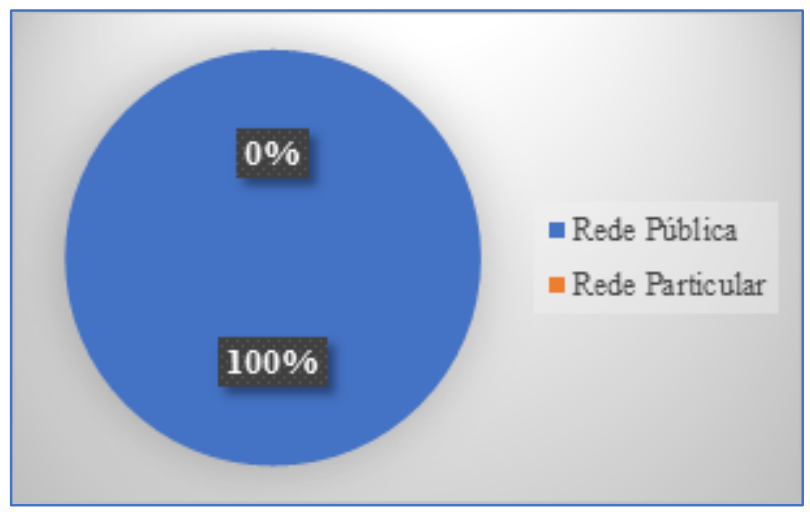

Fonte: Autores (2020).

Gráfico 9 - Primeira opção de escolha de curso no SISU

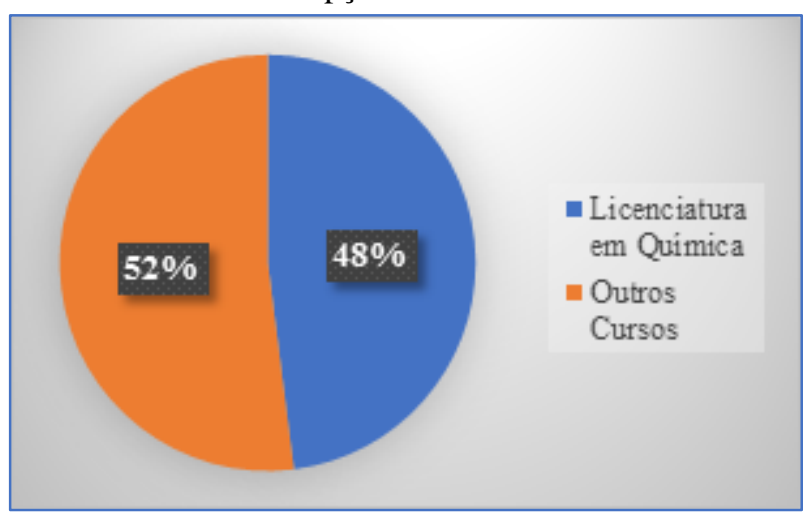

Fonte: Autores (2020).

O fato de todos os alunos terem cursado o ensino médio em escolas públicas, e de mais da metade deles estarem no curso de Química pela baixa nota alcançada no Exame Nacional do Ensino Médio (a nota de corte deste curso em ampla concorrência em 2018 foi de 568,14 
pontos), considerando que $52 \%$ desejaram estar em outro curso de nota de corte maior, mostra que há uma relação entre o nível de aprendizagem (baixo) e o alcance real dessa aprendizagem nas escolhas desses estudantes. Segundo Yamaguchi e Silva (2019) “os índices elevados de reprovação podem ocorrer pela pouca afinidade com o curso selecionado, fragmentação da estrutura curricular, dificuldades de adaptação à organização universitária e fatores endógenos inerentes à relação ensino e aprendizagem, e exógenos, como motivações financeiras” (p. 346).

Outro aspecto da natureza desses dados diz respeito à falta de identidade dos alunos com um curso inicialmente não escolhido por eles. Esta $2^{\mathrm{a}}$ opção normalmente é feita observandose a nota de corte, nesse caso a mais baixa, e não porque o aluno tenha domínio do conteúdo. Uma vez dentro do curso, em contato com as dificuldades naturalmente inerentes ao estudo da química, o aluno passa a vivenciar conflitos para os quais não se preparou, momento em que as reprovações e desistências são potencializadas.

Segundo Sparta, Bardagi e Andrade (2005), a escolha profissional não é um fato isolado emergente em determinado momento da vida, mas deve estar associada a um amplo processo de autoconhecimento e apreciação do setor laboral, pois "informações realistas sobre o mundo profissional costumam estar relacionadas a escolhas mais consistentes e seguras" (p. 80).

Observe no Gráfico 10 que essas desistências passam antes pelo abandono das aulas, pois à medida que o semestre avança fica menor a participação.

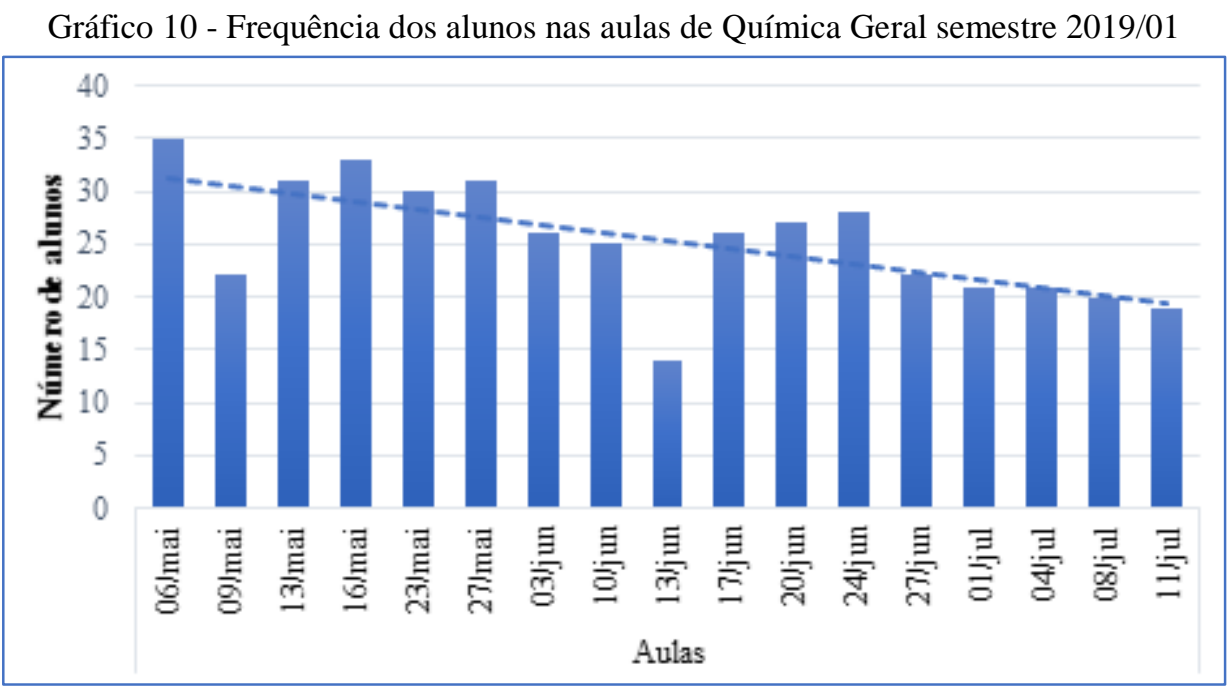

Fonte: Curso de Licenciatura em Química (2019).

Esta baixa frequência nas aulas à medida que o semestre avança é diretamente proporcional aos abandonos, sobretudo depois das notas evidenciadas na primeira avaliação, como podemos observar o Gráfico 11. 


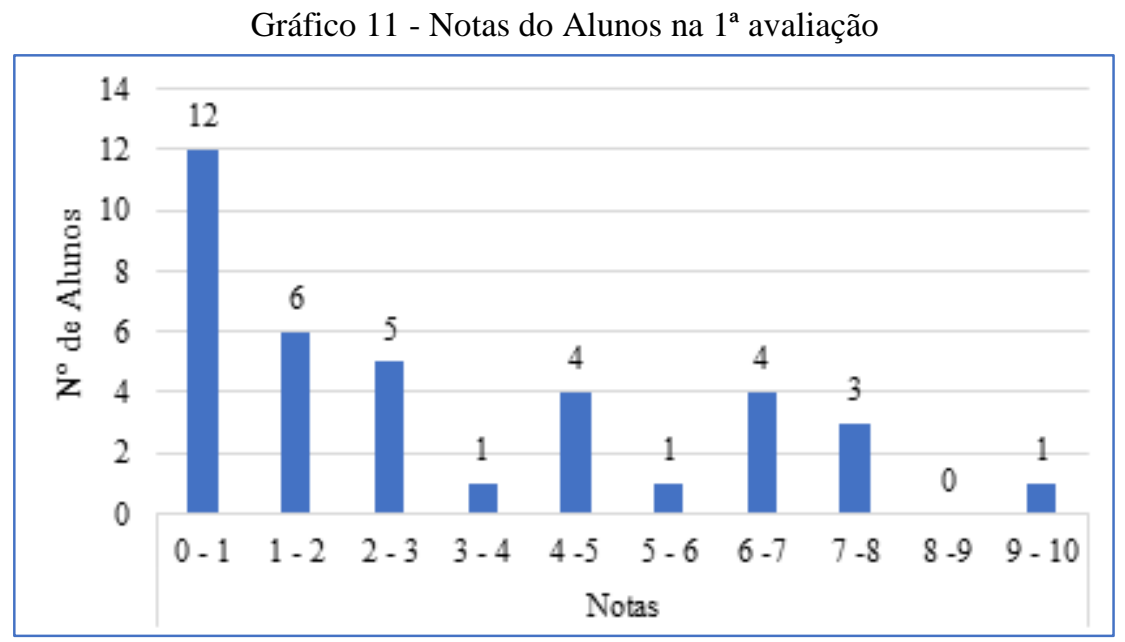

Fonte: Curso de Licenciatura em Química (2019).

Há uma eminente preocupação dos professores que trabalham a disciplina de química geral com a primeira prova, pois é o momento, após dada a nota, onde ocorre o maior número de desistências. Essas desistências não são imediatamente identificas, dado que os alunos não a verbalizam; há uma intensificação das faltas e diminuição da entrega de atividades, caracterizando uma desistência parcial. Esse descompromisso culmina, quase sempre, em reprovação por média, reprovação por média e falta ou desistência.

O gráfico 11 mostra que $42 \%$ dos alunos podem ter alcançado a nota mínima (5 pontos), e que $57 \%$ deles amargaram a pior nota possível (entre zero e um ponto). No acompanhamento que fazemos (observação participante em sala de aula), não raro percebemos dúvidas relacionadas a conceitos básicos, entre as quais como fazer uma consulta na tabela periódica ou realizar um cálculo de densidade de um sólido. Isso poderia ser resolvido na monitoria, mas é mínima a participação, conforme aponta o Gráfico 12.

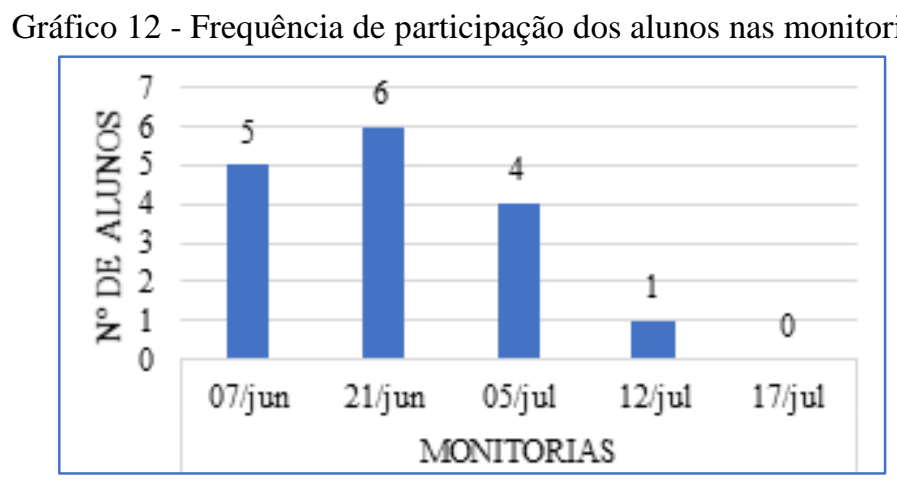

Fonte: Curso de Licenciatura em Química (2019).

Os poucos participantes nas monitorias ofertadas demonstraram relevante dificuldade na enculturação da linguagem química e na realização de cálculos matemáticos. Os alunos não reconhecem símbolos (elementos químicos, íons, modelos atômicos), não conseguem ler uma 
equação química, não conseguem operar matematicamente com frações, notação científica, porcentagem, potência de base 10 e frações, não realizam conversões de unidades de medida (volume, temperatura etc.), diferenciam com dificuldade um fenômeno físico de um fenômeno químico, além da dificuldade em reconhecer subpartículas atômicas.

Essa realidade traduz o quadro de exclusão no contexto da disciplina de química geral, e também confirma nossa hipótese de que a transição do ensino médio para o ensino superior não traz consigo o mérito da aprendizagem. Se entendemos que a entrada desses alunos num curso universitário representa uma forma de inclusão, é aqui, no ensino superior, que temos que garantir sua permanência e sua aprendizagem.

\section{CONSIDERações Finais}

Nossa pesquisa ainda terá, no semestre 2020/1, a oportunidade de realizar intervenções de aprendizagem junto aos novos alunos calouros. Isso será importante, pois as limitações que estamos identificando agora, com a pesquisa participante, nos auxiliarão no sentido de entender melhor a realidade, o que pode qualificar ainda mais a intervenção.

Corroborando com isso, em 2020/1 (semestre letivo tinha início previsto para abril deste mesmo ano, mas atrasou em função da pandemia de Corona Vírus) o curso de Licenciatura em Química da UFMT/Campus Araguaia iniciará um novo Projeto Pedagógico de Curso (PPC), totalmente reformulado. A disciplina de química geral, nesse contexto, passará por uma mudança importante, ou seja, ela foi particionada em outras três disciplinas (Química Básica, Fundamentos de Química e Química Geral Experimental) e teve sua carga horária dobrada de 96 para 192 horas. Essa mudança se deu sobretudo pela compreensão que o grupo de professores imprimiu ao problema de deficiência de aprendizagem dos alunos ingressantes, aquele que reflete com mais força nas reprovações.

Dos nossos dados, fica a certeza da necessidade de um melhor investimento na aprendizagem em química, tanto no ensino médio quanto na universidade. Considerar todas as questões de inerência a este investimento é fundamental, entre elas pensar diferentes formas de abordagem dos conceitos em sala de aula, intensificar aulas práticas e de campo, promover investigações, diversificar instrumentos e critérios de avaliação, desenvolver projetos capazes de promover alfabetização científica e gosto pela ciência, e introduzir, sempre que possível, o uso de novas tecnologias no ensino. Todas essas alternativas podem corroborar para a mudança do quadro atual de exclusão, mas principalmente podem tornar mais humano o processo de ensinar e aprender química na escola e na universidade. 


\section{REFERÊNCIAS}

ARAÚJO, Léia Souza Alves de. Práticas e representações sociais sobre reprovação: um estudo no curso de engenharia elétrica da Universidade Federal de Uberlândia.

Dissertação (Mestrado). Universidade Federal de Uberlândia, Programa de Pós Graduação em Educação, 2003.

BELO, Taciane Nascimento; LEITE, Luiza Beatriz Paixão; MEOTTI, Paula Regina Melo. As dificuldades de aprendizagem de química: um estudo feito com alunos da Universidade Federal do Amazonas. Scientia Naturalis, Rio Branco, v. 1, n. 3, p. 1-9, 2019. Disponível em: https://periodicos.ufac.br/index.php/SciNat/article/view/2540. Acesso em 29/01/2020.

CHASSOT, Attico Inacio. Para que(m) é útil o ensino? Alternativas para um ensino (de Química) mais crítico. Canoas: Ed. Ulbra, 1995.

CHASSOT, Attico Inacio. Diálogos de aprendentes. In: SANTOS, Luiz Pereira dos; MALDANER, Otavio Aloisio (Org.). Ensino de química em foco. Ijuí: Unijuí, 2010.

CHIZZOTTI, Antônio. Pesquisa qualitativa em Ciências Humanas e Sociais. Petrópolis, RJ: Vozes, 2006.

CRESWELL, John W. Investigação qualitativa e projeto de pesquisa. Escolhendo entre cinco abordagens. São Paulo: Penso Editora LTDA; 2014.

CURY, Daniel Gonçalves. A relação entre professor e aluno no ensino superior vista por meio da reprovação. Dissertação (Mestrado). Universidade Federal de Uberlândia, Programa de Pós Graduação em Psicologia, 2012. Disponível em:

http://www.pgpsi.ip.ufu.br/sites/pgpsi.ip.ufu.br/files/Anexos/Bookpage/DissertacaoDanielGo ncalvesCury.pdf. Acesso em 29/01/2020.

FLICK, Uwe. Introdução à Metodologia de Pesquisa: um guia para iniciantes. Tradução de Magda Lopes e Dirceu da Silva. Porto Alegre: Penso, 2013.

LUCKESI, Cipriano Carlos. Avaliação da Aprendizagem Escolar: Estudos e Proposições. 22. ed., São Paulo: Cortez, 2011.

MORTIMER, Eduardo Fleury. Linguagem e formação de conceitos no ensino de ciências. Belo Horizonte: Ed. UFMG, 2000.

OLIVEIRA, Maria Cristina Araújo de; RAAD, Marcos Ribeiro. A existência de uma cultura escolar de reprovação no ensino de Cálculo. Boletim GEPEM, Seropédica/RJ, nº 61 - p. 125-137, jul. / dez. 2012. Disponível em:

http://www.ufjf.br/mestradoedumat/files/2011/09/Produto-educacional-Marcos-Raad.pdf.

Acesso em 18/01/2020.

QUEIROZ, Cecília Alves Pontes de, MOITA, da Silva, F. M. G. Fundamentos Sóciofilosóficos da educação: As tendências pedagógicas e seus pressupostos. Campina Grande; Natal: EPB/UFRN, 2007.

SAMPIERI, Roberto Hernández; COLLADO, Carlos Fernando; LUCIO, Pilar Baptista. Metodologia de Pesquisa. 5. Ed. Porto Alegre, AMGH, 2013. 
SCHNETZLER, Roseli Pacheco. Apontamentos sobre a história do ensino de química no Brasil. In: SANTOS, Luiz Pereira dos; MALDANER, Otavio Aloisio (Org.). Ensino de química em foco. Ijuí: Unijuí, 2010.

SILVA, Glauco Peres da. Análise de evasão no ensino superior: uma proposta de diagnóstico de seus determinantes. Avaliação, Campinas; Sorocaba, SP, v. 18, n. 2, p. 311-333, jul. 2013. Disponível em: http://www.scielo.br/scielo.php?pid=S1414-

$40772013000200005 \&$ script=sci_abstract\&tlng=pt. Acesso em 25/01/2020.

SILVA, Rosenir Rita de Cássia Moreira da; MAINIER, Fernando Benedicto; PASSOS, Fabio Barboza. A Contribuição da disciplina de introdução à engenharia química no diagnóstico da evasão. Ensaio: aval. pol. públ. Educ., Rio de Janeiro, v.14, n.51, p. 261-277, abr./jun. 2006. Disponível em: http://www.scielo.br/scielo.php?pid=S0104$40362006000200008 \&$ script=sci_abstract\&tlng=pt. Acesso em 25/01/2020.

SPARTA, Mônica; BARDAGI, Marúcia Patta; ANDRADE, Ana Maria Jung de. Exploração vocacional e informação profissional percebida em estudantes carentes. Aletheia, Canoas, v. 22, p. 79-88, 2005. Disponível em:

http://pepsic.bvsalud.org/scielo.php?script=sci_arttext\&pid=S1413-03942005000200008. Acesso em 20/01/2020.

TINTO, Vincent. Leaving college: rethinking the causes and cures of student attrition. 2 . ed. Chicago: University of Chicago Press, 1993.

VIÑAO, Antônio. História das disciplinas escolares. Revista Brasileira de História da Educação. Campinas, SP. SBHE/Editora Autores Associados. Jan./jun, no. 18 Set/dez 2008. Disponível em: http://www.periodicos.uem.br/ojs/index.php/rbhe/article/view/40818/21292. Acesso em 15/01/2020.

VIGOTSKI, Lev Semenovitch. Pensamento e Linguagem. $4^{\text {a }}$ ed. São Paulo: Martins Fontes, 2008.

YAMAGUCHI, Klenicy Kazumy de Lima; SILVA, Jath da Silva e. Avaliação das Causas de Retenção em Química Geral na Universidade Federal do Amazonas. Quim. Nova, Vol. 42, No. 3, 346-354, 2019. Disponível em: http://www.scielo.br/scielo.php?pid=S0100$40422019000300346 \&$ script=sci_abstract\&tlng=pt. Acesso em 15/01/2020.

Recebido em: 28 de fevereiro de 2020 . Aprovado em: 29 de abril de 2020. 